\title{
Brief Discussion about the Problems in the Budget Performance Management of Hydraulic Institutions and Countermeasures
}

\author{
Yang Jing and Qie Chao \\ The Pearl River Hydraulic Committee Pearl River Hydraulic Scientific Research Institute \\ Guangzhou, Guangdong 510611
}

\begin{abstract}
A report of the 19th National Congress of the Communist Party of China was proposed to establish a comprehensive, standardized, transparent, scientific, and binding budget system to fully implement performance management. This article starts with the budget management work experience, and then analyzes the problems in the budget performance management of current hydraulic basic institutions from four aspects, including the performance objective, the performance supervision, the implementation of the performance evaluation, the feedback and application of the performance evaluation result, and then give corresponding suggestions, so as to provide some thoughts for the reform of current budget performance management.
\end{abstract}

Keywords-Budget performance management; Performance target; Performance supervision and performance evaluation

\section{DEFINITION OF Budget PERFormance MANAGEMENT}

This article adopts the ministry of finance to define the budget performance management [1]: budget performance management is a comprehensive system jointly constituted by performance objective management, performance supervision management, performance evaluation implementation management, performance evaluation result feedback and application management. The budget performance management procedures are as shown in Figure 1.

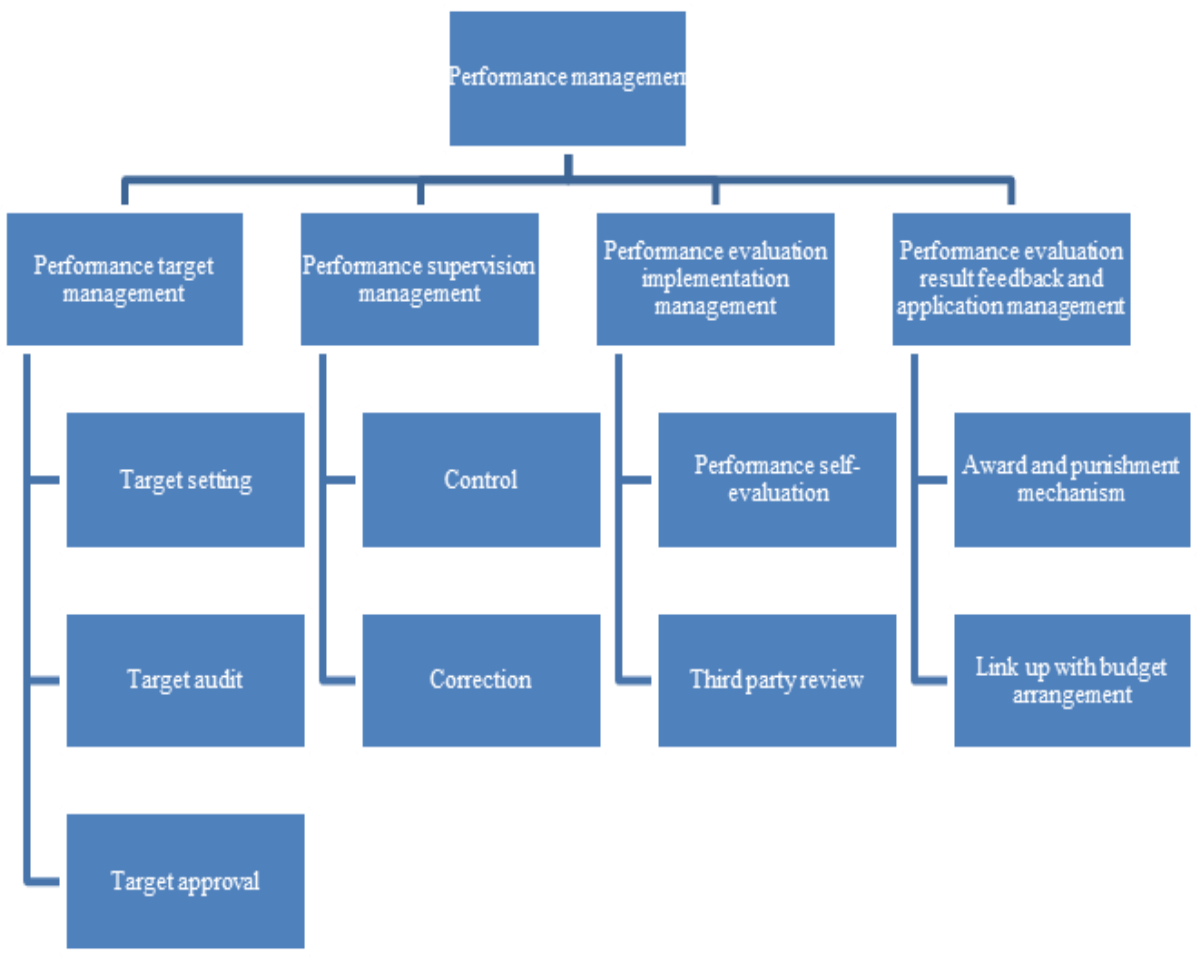

Fig. 1. Budget Performance Management Flow Chart 


\section{A. Performance Objective Management}

Performance target setting; when compiling the budget, the budget unit should scientifically and reasonably calculate the fund demand as per the specific deployment, department function and career development plan of the superior competent department as well as the input and output conditions of the project, compile budget performance plan, and submit the performance target. Performance target setting should mainly include what to evaluate, how much is the best and how to evaluate.

Performance target audit; as per certain performance evaluation method, the superior competent department should audit the correlation between the performance target and department functions of the subordinated budget units, the feasibility of methods adopted for realizing the performance target, the scientificity for performance index setting, and the reasonability of funds requested for realizing the performance target, etc.

Performance target approval; the Ministry of Finance should approve performance target during unit budget approval The budget unit should make comparison during the performance operation track and supervision management supervision and performance evaluation implementation management as per the performance target approved thereby.

\section{B. Performance Supervision Management}

Budget unit should establish performance operation track and supervision mechanism, periodically collects performance operation information for compiled analysis, and conducts track management and supervision inspection on the operation conditions of performance objective; in case of finding any deviations of the performance operation objective away from the expected performance target, it is requested to timely adopt measures for correction. Through control and correction, promote the successful realization of performance target.

\section{Implementation of the Management of Performance Evaluation}

Firstly, the budget unit should conduct self-evaluation about the budget execution conditions, submit the budget performance report, compare the actually obtained performance with the performance target; in case of failing to realize the performance target, it is requested to explain the reasons. Secondly, the superiors should organize and carry out key project performance evaluation, and analyze the problems reflected in the research evaluation result. Finally, the financial department should conduct spot check and recheck about the performance evaluation work of key projects in the budget unit, and meanwhile, assign third party agency to recheck the site, and finally confirm the performance evaluation result and formulate improvement measures.

\section{The Feedback and Application Result Management of Performance Evaluation}

As for the superior competent department and budget execution unit, it is requested to perfect the management system, improve management measures and reinforce expenditure responsibilities as per the performance evaluation result; link up the performance evaluation result with the budget arrangement, and as for units with bad performance evaluation result, decrease the budget for next year; as for units with good performance evaluation result, political support is provided, so as to optimize resource configuration.

\section{CURRENT PROBLEMS EXISTING IN THE BUdGET PERFORMANCE MANAGEMENT OF HYDRAULIC INSTITUTIONS}

\section{A. Performance Objective Management Is Not Refined Enough}

During the project reserve period, the setting of common indexes in performance target should be uniformly executed as per the Common Index System Framework for Secondary Project, and featured indexes can be independently set. Some projects cannot obtain too many indexes in the common index system, but since the basic units generally hold the idea of avoiding trouble whenever possible, they won't supplement corresponding featured indexes, so this may result in the performance objective of some projects being not so comprehensive and correct enough.

There are few quantitative indexes in performance index, and the commonly seen quantitative indexes, such as the achievement report quantity, whether the project can pass acceptance and the setting of these indexes are relatively simple, and the proportion of weight for these output indexes in the grading system is $50 \%$. There are too many qualitative indexes, which mainly are benefit index (economic benefit index, ecological benefit index, social benefit index and sustainable influencing index), but these indexes are hard to be quantized, and the performance evaluation information is hard to be obtained, which can cause the unreliable evaluation result.

\section{B. Performance Evaluation Process Is Not Rigorous Enough, and the Performance Evaluation Quality Remains to be Improved}

The performance operation supervision of basic units is not in place, and the executed supervision has no substantive measures, and the project undertaking unit merely needs to fill in several performance target completion values in the budget system, without correction link, or the in-depth analysis about the reasons generating the deviation from standard, so as to further think about whether the performance objective is appropriate (whether it is set high or low).

The performance evaluation is still the post-evaluation focused on project acceptance, and it's only target is evaluation, and lacks in pre-evaluation and process evaluation.

Few pilot performance evaluation projects are selected in the performance evaluation, with small amount, and they cannot intensively reflect the core function of the department. 


\section{B. ReinforcingProcess Management, and Establishing the Communication and Feedback Mechanism in Performance Evaluation}

The communication and feedback mechanism should run through the full process, including the performance target setting, performance target supervision, performance evaluation result, and performance evaluation application. Effective communication and feedback mechanism should fully play the leading role of performance target during the former, middle and later periods of project implementation, and avoid the performance evaluation from changing into a process of post remedy. For the reinforcement of performance operation supervision mechanism, it is requested to see the output result, timely find out problems and timely make correction, but also analyze the good and bad reasons for generating the deviation from standard, so as to further reflect whether the thought performance target is appropriate (whether the target is set high or low), whether the uncontrollable factors have hindered the completion of target, and whether there are good communication mechanism to timely adopt remedial actions for the behavior about the deviation from standard. Through analyzing reasons, make sure the reasonability and safety of budget fund expenditures.

Reinforce the strength for introducing the third party evaluation, so $s$ to improve the evaluation quality, ensure the objectiveness and justice of the performance evaluation result, and fully play the independence and specialty of a third party institution.

\section{Promoting Performance Evaluation Result Feedback, and Reinforcing Application Management}

The performance evaluation result should not only evaluate the previous performance, but also reflect the improved orientation, and solve the existing problems in the budget plan of next year.

Performance evaluation is also a valid approach for understanding the performance of project principal in plan, execution, control and other aspects, and ensuring that the project principal can truly and validly conduct budget management, and it is requested to link up individual awards and punishment with the performance evaluation result of budge fund [6].

Make perfection from the mechanism, link up the budget arrangement with performance evaluation result, and gradually establish the budget performance management mechanism of "evaluating after budget completion, giving feedbacks about the evaluation result, and applying feedback results" [6].
Supplement the setup of individual index library, perfect the performance evaluation index library, and establish scientific and valid evaluation system. 


\section{CONCLUSION}

This article starts from the definition of budget performance management, combines the budget management work experience, and then analyzes the problems in the project fund of current hydraulic basic institutions considering four aspects, including the performance target management, the performance supervision management, the performance evaluation implementation management, the performance evaluation result feedback and application management, and meanwhile, puts forward relevant suggestions for corresponding problems.

\section{A. Performance Target Management Is the Emphasis in Budget Performance Management}

Since the budget unit will carry out the follow-up performance supervision, and performance evaluation as per the performance target approved thereby, so the performance target management can decide the overall quality of budget performance management. The suggestion is to confirm the index system for performance target management through science, and make the performance target evaluation operational, to further reinforce the performance objective management. The suggestion is to accelerate the training and promotion for the performance target management of basic units, and firmly establish target management awareness.

\section{B. Active Exploration Is the New Mode for Budget Performance Management}

Budget performance management is an innovative work, and shouldn't be restricted to the existing work method and work thought, and should actively explore new mode. For instance, in March, 2018, the same level of budget performance management in Shenzhen City introduced 18 third party institutions to participate in budget performance management. The suggestion is to change the mode of performance evaluation, and gradually convert single subject evaluation mode focused on performance self-evaluation and project acceptance to the objective evaluation mode focused on a third party agency. On one hand, this can fully play the independence and specialty of the third party institutions, but also ensure the objectiveness, fairness and reliability of evaluation result [7].

\section{Reinforcing the Application of Performance Evaluation Result}

Award and punishment are the last step for performance management, and lack in corresponding incentive and constraint mechanism, and cannot exert the effect of budget performance management. The evaluation result should link up with the future budget arrangement and individual award and punishment, for instance, the Ministry of Water Resources established budget management three-term mechanism in September, 2013 [8], to ensure that it can exert an important role in budget execution progress and quality. The suggestion is to establish corresponding performance management methods at the advanced pilots of the Ministry of Water Resources, and explore the performance evaluation result and budget arrangement, and the specific implementation methods for linking up the performance evaluation result with budget arrangement and individual awards and punishment.

\section{ACKNOWLEDGMENT}

About the First Author: Yang Jing (1986-), female, Mailing Address: 706, No. 80, Tianshou Road, Tianhe District, Guangzhou City,

Tel.: 13929567959, Fixed Phone No.: 020-87117208. Email:127644310@qq.com

About the Second Author: Qie Chao (1973- ), female, Mailing Address: 706, No. 80, Tianshou Road, Tianhe District, Guangzhou City.

\section{REFERENCES}

[1] Wang Haitao. Research about the Reform of Budget Performance Management in our Country [D]. Institute of Financial Science for the Ministry of Finance, 2014.

[2] Song Yue. Current Status and Suggestions for the Financial Fund Budget Performance Management of Water Resources [J]. China Water, 2014 (14): 61-62.

[3] Zhang Wei. Research about the Perfection of Budget Expenditure Performance Evaluation System [D]. Institute of Financial Science for the Ministry of Finance, 2015.

[4] Accounting Qualification Evaluation Center for the Ministry of Finance. Senior Accounting Practice [M]. Economic Science Press, 2017.

[5] Budget Division for the Ministry of Finance. Central Department Budget Compilation Guidance 2018[M]. Economic Science Press, 2017.

[6] Weihrich, Koontz. Management Science---Globalization Perspective [M]. Economic Science Press, 2004

[7] Website of the Ministry of Finance, http://www.mof.gov.cn/index.htm

[8] Website of the Ministry of Water Resources, http://www.mwr.gov.cn/. 